\title{
IDEA and Family Involvement
}

\author{
Mehmet Emin ÖZTÜRK
}

\section{ARTICLE INFO \\ Article History: \\ Received 03.07.2016 \\ Received in revised form \\ 19.10.2016 \\ Accepted \\ Available online 01.01.2017}

\begin{abstract}
Individuals with Disabilities Education Act (IDEA) gives many rights to parents with special needs in terms of involvement and participation. Given the importance of family involvement in the special education process, and federal legislation that increasingly mandated and supported such involvement over time, considerable research has focused on the multiple ways that relationships between schools and families in the special education decision making process have played out. Educational professionals should create a positive climate for CLD families so that they feel more comfortable and therefore are able to participate more authentically and meaningfully.
\end{abstract}

(C) 2017 IJERE. All rights reserved

Keywords:

IDEA, Special education, Parent involvement, family school collaboration.

\section{IDEA AND FAMILY INVOLVEMENT}

The partnership between the family of a student with disabilities and a school is very important in the special education process because a supportive family structure contributes positively to the education and progress of students with disabilities (Hess, Molina \& Kozleski, 2006). Families, and specifically parents, know their child's needs best and are therefore positioned to assert their child's interests and make decisions as to what is educationally appropriate for him or her (Lo, 2010). Parents are able to provide educators with insight into how their child functions and how to best approach him or her to succeed as they know about their own children's strengths and challenges from years of nurturing them (Wang, Mannan, Poston, Turnbull, Summers, 2004).

This paper will discuss the policy related to family school collaboration addressed in the Individuals with Disabilities Education Act (IDEA). Historically, decisions about the education of students with disabilities have been up to medical and educational professionals to the extent that families have been left out of the process altogether, or provided little opportunity to weigh in (Ferguson, 2008). Public Law 94-142 was past to help families united in a struggle for the civil rights of children with disabilities. The parents of children with disabilities who sought out passage of the law were not willing to accept the lack of access to public education, nor the ways in which families were positioned by professionals as powerless in making educational decisions for their own children. For the first time, this federal law enacted by Congress on November 29, 1975 guaranteed parents' rights to participate in the special educational planning for their children (Klein, 2009). More specifically, PL 94-142 regulated free and appropriate public education for all children with disabilities, at no expense to the parent and child and individualized education program (IEP) prepared by a team which includes the parents.

In 1990, PL 94-142 was reauthorized by Congress as the Individuals with Disabilities Education Act (IDEA). IDEA has since been reauthorized in 1997, 2001, and 2004, and over time changes to IDEA have reflected both more and less emphasis on parent participation and related rights. IDEA 1990 expanded parent participation by viewing parents as equal partners in decision making particularly related to decisions about the development of students' Individualized Education Plans (IEPs) (i.e., the documents that describes the educational program that has been designed to meet that child's disability-related unique needs). Later reauthorizations continued to build upon emphases of parents as collaborative partners in special education with regard to eligibility, service, and placement decisions (Individuals With Disabilities Education Act, 20 U.S.C. § 1400 (2004).

Currently, IDEA asserts the necessity of relationships between parents/guardians and schools by emphasizing educational supports and standards for their involvement (Duquette, Fullarton, Orders, 
Robertson-Grewal, 2011, Harry, 2008), including the role of the local education agency in informing parents about their rights for their child's education (Kalyanpur, Harry, \& Skrtic, 2000). To date, parents' rights as formalized in IDEA include receiving a complete explanation of IDEA's procedural safeguards, inspecting and reviewing their child's educational records, participating in meetings, obtaining an independent educational evaluation, receiving prior written notice of any proposed changes to their child's services, placement, or eligibility-related assessment, giving consent for proposed changes, and disagreeing with the decisions made by the school members of their child's educational team (Individuals With Disabilities Education Act, 20 U.S.C. § 1400 (2004).

Given the importance of family involvement in the special education process, and federal legislation that increasingly mandated and supported such involvement over time, considerable research has focused on the multiple ways that relationships between schools and families in the special education decisionmaking process have played out. In general, while some research has provided examples of what truly collaborative relationships look like (see for example, Angell, Stoner, \& Shelden, 2009), much of the literature points to significant problems with these relationships and their outcomes in the form of parents obtaining insufficient or inaccurate information about special education services (Nespor \& Hicks, 2010, Duquette, Fullarton, Orders, \& Robertson-Grewal, 2011).

Merely including parents in IEP meetings is not enough; parent and student knowledge and input must be central to special education decision making, and the rights guaranteed to parents under IDEA must be fully carried out. Yet this is all too often not the case. For example, research has demonstrated instances in which it is not typical practice for school personnel to invite parents to discuss issues related to IEP development (Duquette, Fullarton, Orders, Robertson-Grewal, 2011). Relatedly, special education teachers prepare IEPs in isolation and prior to IEP meetings according to the required information for each section as set by the state procedures for doing so (Hess et al., 2006). Therefore, once the IEP meeting occurs, there is very little opportunity for generating new ideas on the basis of parental input. This may be thought by some schools to be efficient IEP development, but if parents are not involved in every decision in the IEP process, major or minor, there is potential to neglect or insufficiently address sections that may be of great importance to the parents. When parents are not provided opportunities to make decisions about the level of support provided by the IEP, students may not get adequate accommodations or modifications of the general education curriculum (Nespor \& Hicks, 2010).

Other areas in which the research has demonstrated problems with school-family partnerships in the special education process are related to communication and power. In regard to the former, professionals have been shown to over-rely on jargon (i.e., professional language) or acronyms in special education meetings, resulting in parents not having access to enough or accurate information upon which to contribute to or raise questions about special education decisions. To illustrate, Dabkowski (2004) stated that unexplained jargon like classification notes and presenting of test results are generally misunderstood by parents, which creates a scenario in which parents must rely on the decisions of the school professionals without understanding what those decisions entail.

Related to power, other studies have demonstrated the disproportionate authority of certain school professionals in making special educational decisions as compared to other school professionals and parents. For example, Rogers (2002) studied the discourse used by school professionals and the parent of one student with a disability across two IEP meetings and found that school professionals all but forced the parent and child to make a decision that the school professionals believed to be best, rather than providing information for the parent and child to formulate their own conclusion.

Despite the importance of family involvement guaranteed by IDEA, these issues with the quality and outcomes of school-family relationships within the special education decision making process and throughout the educational trajectory of students with disabilities are exacerbated for families from groups traditionally marginalized in U.S. public schools: namely, culturally and linguistically diverse (CLD) families.

For the purposes of this paper, I define CLD families as those belonging to minority racial, ethnic, or linguistic group in the United States. I also acknowledge other terms used in research literature to account 
for this population, including historically underserved, and racial and linguistic minority, but have chosen to utilize CLD throughout the review for the purpose of consistency.

Researchers have concluded that increased problems exist with regard to the collaborative relationship between CLD families and school professionals in the special education process for what this paper sum up as three major reasons based on my review of research on parent participation in special education, in general. The first reason I characterize as structural barriers to participation in the special education process for culturally and linguistically diverse families (Klein, 2009). The second reason is related to cultural differences in the ways in which parental participation in education, as well as disability, are defined (Kalyanpur, Harry, \& Skrtic, 2000). The third reason is deficit-based assumptions about CLD families held by school professionals (Harry \& Klingner, 2006). All of these reasons ultimately contribute to problematic outcomes for CLD students with disabilities: most notably perhaps the disproportionate representation of CLD students in special education (Artiles, 2003) and more restrictive educational placements as compared to their White peers (Sullivan, 2011). I provide a brief review of the literature related to these reasons for problematic collaboration between school personnel and CLD families in the next two sections, interweaving discussion of unfavorable outcomes stemming from these problems.

Structural barriers to CLD family participation in special education. Myriad structural barriers limit authentic and collaborative relationships between schools and CLD families, particularly in regard to special education. According to Kalyanpur, Harry, and Skrtic (2000) these barriers include families' economic circumstances such as lack of transportation or child care, and language differences as compared to school professionals.

For example, with regard to language issues, parents may not speak English and schools often do not provide adequate translation services, school communication in written English is often beyond parents' literacy level, and the use of only English in schools prevents parents' active participation in school meetings and events (Lo, 2008). All of these barriers contribute to problems with special education collaboration between school personnel and CLD families, many of whom may lack understanding of their rights and understandings of the special education system in the U.S. (Childre \& Chambers, 2005, Lo, 2010). Harry and Klingner (2006) found, in their book-length study of the reasons minority students were overrepresented in a CLD school district, problems that made it very difficult for parents to understand this system, including a lack of availability of translation and interpretation services related to special education processes and within special education meetings. Also, IEP meetings are often held during the day, making it difficult for working parents to participate.

Disproportionality is an outcome of the structural barriers in the socio-political context in the United States. Disproportionality is overrepresentation in special education of CLD students with disabilities or under-representation in gifted and talented programs of CLD students with disabilities. When CLD students are so easily labeled as special education, it "has negative effects on self-esteem and may reduce the likelihood that special education students will be able to successfully integrate into the larger society as adults" (Ahram, Fergus, \& Noguera, 2011, p. 2235). In addition to that, Harry and Klingner (2006) stated that students get limited curriculum when they stay in special education; expectations of students are lower; and disproportionality causes racial segregation.

\section{DISCUSSION}

Differences in cultural norms between CLD families and school professionals. One of the most marked ways in which difference in cultural beliefs impacts school-family collaboration is related to varying beliefs about disability held by CLD groups. For example, parents may interpret that having a child with disabilities is a punishment for past wrongs and accordingly do not seek help from professionals because of social stigma (Lo, 2010; Klein, 2009). In many Asian cultures, it is not appropriate for parents of children with disabilities to discuss their child's problems with people outside of family because they think it may damage the pride of family (Lo, 2010). However, in Latino families, including extended family members in special education processes for their support and opinions is very common (Klein, 2009). In addition, unlike Asian families, Latino families may be more willing to talk more about their children's problems with other people outside the family (Salas, 2004). 
Accordingly, school professionals of dominant cultural backgrounds who view disability as a biological condition which should be openly addressed in schools through special education, may interpret lack of parent participation in special education as disinterest or apathy, when instead, it is what is appropriate, given the cultural norms of the family.

One of the other ways in which differences in cultural beliefs impacts collaboration between CLD families and school professionals is related to how participation is defined or considered appropriate, if at all. The principle of parent participation in special education is based on norms associated with the dominant culture, and school professionals may expect that parents should understand the expectations and cultures of professionals (Kalyanpur, Harry, \& Skrtic, 2000). Yet, parents may have very different beliefs about what is appropriate. For instance, many Hispanic families do not want to attend meetings because they think that they have limited English and they do not believe that they will make a difference even if they attend. Some Hispanic families even have a fear that their children will be suspended if they complain about school decisions (Leon, 1996, as cited in Kalyanpur, Harry, \& Skrtic, 2000).

Professionals' deficit-based assumptions about CLD students and families. Munn-Joseph and Gavin-Evans (2008) assert, "generally, discussion of the family-school relationship in urban schools serving low SES or ethnic minority children and their families focuses on the incongruence between the family and school personnel" (p. 378). This incongruence is mainly based on faulty perceptions of CLD families by school professionals; the U.S. education system is built upon the norms and values of the majority white, middle class U.S. culture (Hess, Molina, Kozleski, 2006).

Furthermore, most U.S. teachers are of European American descent and have a middle-class background, which contributes to barriers between teachers and a lack of understanding of the culture of parents from different backgrounds, which has significant implications for how school professionals explain the academic performance of CLD students (Hess, Molina, \& Kozleski, 2006; Trainor, 2010). Research has demonstrated that teachers have attributed academic struggles of ELLs to disability, rather than typical performance in light of the students English language acquisition (Klinger \& Harry, 2006). Relatedly, students who are ELLs are disproportionately referred to and found eligible for special education in some districts and states (Artiles, Rueda, Salazar, \& Higareda, 2005). Other studies have found the overrepresentation of African American students as Emotionally Disturbed, and in segregated (i.e., separate) special educational placements as compared to their White counterparts with the same disability diagnosis as related to teachers' bias in interpreting the behaviors of African American students as problematic, and more specifically, threatening (Hosp \& Hosp, 2002).

School professionals' deficit assumptions about CLD parents also have implications for how they frame and characterize parent participation in special education (Kalyanpur, Harry, \& Skrtic, 2000). Wang et al. argued that CLD parents "...are often perceived by school personnel to be generally passive and uninvolved in the special education process" (2004, p. 145). Yet, situations in which parents are perceived in this way could be potentially indicative of CLD families' economic difficulties (Harry, 2008; Klein, 2009) (e.g., parents may find it difficult to participate in school activities because of the demands of working many hours for little pay), as well as cultural norms that dictate parents follow educators' decisions and judgments without challenge, as a sign of respect (Klein, 2009).

\section{RECOMMENDATIONS}

Although IDEA and other federal laws or regulations recognize that parents of children with disabilities should have an important role at IEP meetings, cursory participation by family members in the special education process between family and school is not enough. "Parents have a unique understanding of their child's needs, they are often considered to be the best advocates to assert their child's interests and make decisions regarding what is appropriate for him/her" (Lo, 2010, p. 405).

Educational professionals should create a positive climate for CLD families so that they feel more comfortable and therefore are able to participate more authentically and meaningfully. A positive climate should include actively involving CLD families in decision making rather than speaking over them; 
explaining academic or legal concepts which are difficult to understand; and maintaining open communication between school professionals and the families. Educational professionals also need to find a way for a better communication with families whose primary language is not English and/or have limited English proficiency. Some progressive examples of effective communication with CLD families might include providing all written forms and documents in the family's home language and using an interpreter to communicate via phone or at IEP meetings when discussing their child. Educational professionals also need to help CLD families by explaining the special education system, with the knowledge that this system may conflict with or be confusing in light of families' beliefs about disabilities, or the roles parents should play in making educational decisions for their children.

There is a disproportionate power between school professionals and CLD families based on structural barriers families encounter both in schools and in U.S. society, at large. Since school professionals have so much power in educational planning and children's educational placement, they have to be knowledgeable about CLD families' needs and perspectives, while also addressing the imbalance of power that is magnified between themselves and families who are culturally and linguistically diverse. They must emphasize the importance of obtaining input from families regarding any educational decisions, and they should better understand cultural conflicts between CLD families and school cultural norms.

\section{REFERENCES}

Ahram, R., Fergus, E., \& Noguera, P. (2011). Addressing racial/ethnic disproportionality in special education: Case studies of suburban school districts. Teachers College Record, 113, 2233-2266.

Angell, M. E., Stoner, J. B., \& Shelden, D. L. (2009). Trust in education professionals: Perspectives of mothers of children with disabilities. Remedial and Special Education, 30(3), 160-176.

Artiles, A. J. (2003). Special education's changing identity: Paradoxes and dilemmas in views of culture and space. Harvard Educational Review, 73(2), 164-202.

Childre, A., \& Chambers, C. (2005). Family perceptions of student centered planning and IEP meetings. Education and Training in Developmental Disabilities, 40, 217-233.

Dabkowski, D. M. (2004). Encouraging active parent participation in IEP team meetings. Teaching Exceptional Children, 36(3), 34.

Duquette, C., Fullarton S., Orders S., Robertson-Grewal, K. (2011). Insider, outsider, ally, or adversary: Parents of youth with learning disabilities engage in educational advocacy. International Journal of Special Education, 26, 1-18.

Harry, B., \& Klingner, J. K. (2006). Why are so many minority students in special education? Understanding race and disability in schools. New York: Teachers College Press

Hess, R. S., Molina, A. M., \& Kozleski, E. B. (2006). Until somebody hears me: parent voice and advocacy in special educational decision making. British Journal Of Special Education, 33, 148-157.

Hosp, J. L., \& Hosp, M. K. (2002). Behavior differences between African-American and Caucasian students: Issues for assessment and intervention. Education and Treatment of Children. 24, 336-350

Individuals with Disabilities Education Improvement Act of 2004, 20 U.S.C. s 1400168 et seq. (2004).

Kalyanpur, M., Harry, B., \& Skrtic, T. (2000). Equity and advocacy expectations of culturally diverse families' participation in special education. International Journal of Disability, Development and Education, 47, $119-136$.

Klein, J. L. (2009). Participation of culturally, linguistically and economically diverse parents in the special education 
planning process. (Unpublished doctoral dissertation). University of Kansas.

Munn-Joseph, M., \& Gavin-Evans, K. (2008). Urban parents of children with special needs: Advocating for their children through social networks. Urban Education, 43, 378-393

Lo, L. (2008). Expectations of Chinese families of children with disabilities towards American schools. School Community Journal, 18(2), 73-90.

Lo, L. (2010). Perceived benefits experienced in support groups for Chinese families of children with disabilities. Early Child Development \& Care, 180, 405-415.

Nespor, J., \& Hicks, D. (2010). Wizards and witches: Parent advocates and contention in special education in the USA. Journal of Education Policy, 25(3), 309-334.

Rogers, R. (2002). Through the eyes of the institution: A critical discourse analysis of decision making in two special education meetings. Anthropology and Education Quarterly, 33 (2), 213-237.

Salas, L. (2004). Individualized educational plan (IEP) meetings and Mexican American parents: Let's talk about it. Journal of Latinos and Education, 3, 181-192.

Sullivan, A. L. (2011). Disproportionality in special education identification and placement of English language learners. Exceptional Children, 77(3), 317-334.

Trainor, A. A. (2010). Diverse approaches to parent advocacy during special education home-school interactions: Identification and use of cultural and social capital. Remedial and Special Education, 31(1), 34-47.

Wang, M., Mannan, H., Poston, D., Turnbull, A., \& Summers, J. (2004). Parents' perceptions of advocacy activities and their impact on family quality of life. Research $\mathcal{E}$ Practice for Persons with Severe Disabilities, 29(2), 144-155. 